\title{
Principio de identidad y libertad. La autocritica del idealismo en Schelling
}

Crescenciano Grave

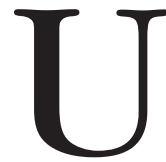

na de las piedras angulares sobre las que se levantó la filosofía moderna es la oposición elemental entre el espíritu y la naturaleza. En el desarrollo mismo de la oposición el espíritu se autodetermina como el lugar exclusivo de la razón y, subjetivizándose, determina a la naturaleza en un doble plano: materialmente como el conjunto de los objetos presentes y susceptibles de ser dados a la intuición sensible y formalmente ordenada por las leyes que el propio sujeto le impone. El levantamiento de esta oposición se origina desde el trazado mismo de la ruta distintiva del pensar moderno.

Esta ruta, dominante en la metafísica moderna, es la que inauguró Descartes mediante su ruptura con el modo antiguo de pensar. El inicio de la filosofía moderna supone una inversión respecto al inicio de la filosofía griega. Y en esta inversión se juega la cuestión del principio. Tales, al plantear la pregunta acerca "de qué es lo primero y lo primordial en la naturaleza de las cosas" entendía el principio "en un sentido objetivo" independiente de nosotros. Descartes, en cambio, se pregunta por lo primero para mí (para el sujeto que piensa) y la respuesta no podía ser otra que yo mismo: lo primero para mí es mi propio ser pensante. Ésta es la primera e inmediata certeza a la cual todas las demás deben vincularse sosteniéndose en ella.

Todo debía ser verdadero sólo en tanto y en cuanto estuviese conexionado con esta certeza inmediata. Por consiguiente, es evidente que la proposición yo soy es, a lo sumo, el punto de partida para mí [...] Por tanto, aquí la filosofía no va más allá de una mera certeza subjetiva y

${ }^{1} \mathrm{~F}$. W. J. Schelling, Lecciones muniquesas para la historia de la filosofía moderna. Trad. de Luis de Santiago de Guervós. Málaga, Universidad de Málaga/EDINFORD, 1993, p. 111. 
ciertamente no sobre el modo de existencia (el único modo propiamente dudoso), sino solamente sobre la existencia de todo lo que está fuera del sujeto. ${ }^{2}$

El modo de proceder cartesiano conduce a reconocer como principio sólo lo que para mí es cierto de manera evidente; conduce sólo a mí mismo, pues sólo yo mismo tengo certeza inmediata de mí.

Éste es, pues, el famoso cogito, ergo sum de Descartes, con el que se dio, por cierto durante mucho tiempo, el tono fundamental -por decirlo así- a la filosofía moderna y que ejerció los efectos de un encantamiento: por el que quedó la filosofía confinada en el círculo de la subjetividad y de los hechos de la conciencia puramente subjetiva. ${ }^{3}$

Para Descartes, pensamiento y ser coinciden inmediatamente en la certeza de la propia existencia. Las cosas externas me las represento, pero la existencia de estas cosas fuera de mí no coincide con su representación en mí: uno es lo representado, otro es el representante. En cambio, con la certeza de que pienso, luego existo conozco el pensamiento y el ser como idénticos de manera inmediata: mi ser se da y se comprende en el pensar; yo soy pensando; mi ser se me da en el acto de pensar. Representado y representante no son uno y otro, son iguales. Sin distinguir entre aquello que piensa y aquello que reflexiona en la posición y posesión del yo por sí mismo, Descartes instaura a la certeza como principio cognoscitivo que, sin embargo, requiere de una garantía desde la cual poder sostener que a nuestras representaciones de las cosas externas les corresponde una realidad. Este garante lo encuentra en Dios, por lo tanto, hay que demostrar su existencia, y esto lo lleva a cabo considerando que el mero hecho de pensar a Dios me hace ver que existe: “[...] existe en mí la idea de un ser absolutamente perfecto [y] a la idea de un ente absolutamente perfecto pertenece la idea de existencia necesaria [...]" ${ }^{4}$ Desde esta apelación a Dios como el garante del conocimiento y como la verdadera esencia de la realidad, Descartes concibe el mundo de los cuerpos de una manera íntegra, pero separado tajantemente de lo espiritual.

Para el inaugurador del principio moderno de la verdad como certeza era imposible concebir un mismo principio para lo espiritual y lo corpóreo. Un

${ }^{2}$ Ibid., pp. 111-112.

${ }^{3}$ Ibid., p. 114. Pese a ser el inaugurador de este encantamiento moderno de la subjetividad, Descartes es $-\mathrm{y}$ Schelling no deja de reconocerlo- el pensador que rompe con el sometimiento de la filosofía a la autoridad externa al pensamiento mismo y que lleva a la filosofía a la conquista de la libertad.

${ }^{4}$ Ibid., p. 118. 
principio que en la materia estuviese degradado, fuera de sí, y en el espíritu se encontrase exaltado, en plena posesión de sí mismo, como ser en sí. ${ }^{5}$ Para Descartes, la materia es un ser meramente externo, sin ninguna interioridad; un producto que en sí mismo no tiene nada del principio productor. El autor de El discurso del método no admite un principio vivo en la extensión y acepta las cosas externas sólo como inertes y, por lo tanto, opuestas a la cosa pensante.

La cosa extensa y la cosa pensante se excluyen mutuamente: lo extenso es lo carente de espíritu; yuxtapuesto, externo, disperso, cuya aparición como consistente es sólo resultado de la presión y del choque externos. Las cosas extensas están compuestas de partes a las que les falta un principio interno de movimiento, que basado en el choque, es puramente mecánico. Lo espiritual, por su parte, es completamente inmaterial y, por ello, carece de toda afinidad con la extensión. La disparidad entre materia y espíritu imposibilita la comunicación, es decir, la una no puede actuar sobre el otro y viceversa. ${ }^{6}$ Y, con esto, Descartes ahonda la separación entre espíritu y naturaleza, pensando a los animales y al cuerpo humano como máquinas complicadas que, en el caso del último, ejecuta sus acciones naturales de una manera totalmente independiente del alma. Desde aquí la conclusión crítica es contundente.

La filosofía de Descartes ejerció su influjo más universal, y al mismo tiempo más funesto, con la escisión absoluta entre materia y espíritu, si bien ellos están absolutamente conexos y se explican y se presuponen mutuamente. De esta forma, destruyó el gran organismo universal de la vida y abandonó tanto las cosas más altas como las más bajas a una concepción muerta, puramente mecánica, que dominó casi hasta tiempos muy recientes en todas las ramas del saber humano $[\ldots]^{7}$

${ }^{5}$ Cf. ibid., p. 127.

${ }^{6}$ Aquí Schelling apunta, por la vía del preguntar crítico, la actividad recíproca entre la cosa pensante y la cosa extensa, apunte que, a la vez, nos da una señal para arribar al modo como él concebirá la relación -que abordaremos más adelante- entre cuerpo y espíritu dentro del conflicto entre libertad y necesidad: "Si ambas no tienen nada en común, ¿cómo pueden hacer y sufrir tantas cosas en común un cuerpo y un espíritu? Como, por ejemplo, cuando el espíritu siente un dolor corporal; o cuando una simple impresión hecha sobre el cuerpo transmite al espíritu y produce una representación en la cosa pensante, o inversamente, cuando una tensión del espíritu, un dolor de nuestra alma, provoca la fatiga en el cuerpo o hace que caiga enfermo; o cuando una idea de nuestro espíritu, como por ejemplo en el acto de hablar, fuerza a órganos puramente corporales a que le sirvan; o cuando una voluntad, una decisión de nuestro espíritu produce un movimiento análogo en la cosa extensa que nosotros llamamos cuerpo" (ibid., p. 129).

${ }^{7}$ Ibid., p. 131. 
Frente al dominio de esta manera de pensar, Schelling, en sus Investigaciones filosóficas sobre la esencia de la libertad humana y los objetos con ella relacionados, ${ }^{8}$ considera que está abierto el camino para una comprensión más adecuada de la oposición a la que plantea no en términos de naturaleza y espíritu sino, superior y verdaderamente, como oposición de libertad y necesidad. "Ya es hora de que aparezca la superior, o mejor dicho, la verdadera oposición: la de necesidad y libertad, con la que llega por vez primera a consideración el punto central más íntimo de la filosofía”?

Al pensar la oposición entre libertad y necesidad, la filosofía se confronta con el núcleo que la define: el pensamiento filosófico no se asume aislado de la oposición, sino constituido por ella misma. La libertad y la necesidad no son objetos ante los cuales la filosofía se sitúe y, desde la exterioridad, se los represente como ajenos a sí misma. La oposición entre libertad y necesidad atraviesa constitutivamente a la totalidad, llegando a expresarse en el ejercicio mismo de la reflexión filosófica. Esta expresión, sin embargo, no culmina en una completa recuperación consciente: al asumir el pensamiento constituido por la misma oposición que en él se expresa, el despliegue de la oposición no se agota en ninguna de sus manifestaciones; ella continúa revelándose como aquello que sostiene el devenir real.

Fundamento y existencia se originan recíprocamente, ya que el despliegue y manifestación de la segunda implica el repliegue y ocultación del primero, y esta contradicción originaria es a la que se alude en términos del conflicto entre libertad y necesidad, conflicto del que todo surge y en donde todo se sustenta. En este conflicto al interior del ser, el ser mismo se afirma en su identidad y alteridad, en su mismidad y diferencia como fundamento y existencia; afirmación en la que el fundamento permanece en la oscuridad al mismo tiempo que la existencia se levanta claramente sin dejar de presuponerse ni disolviéndose mutuamente. Uno de los puntos que confiere potencia histórica al ensayo sobre la libertad de Schelling es que la concepción del conflicto ontológico entre fundamento y existencia se extiende a la presencia de la existencia en tanto tal, convirtiéndose en la clave para pensar al ser humano como aquel ente bajo el cual resuena con una tonalidad propia el mismo conflicto

${ }^{8}$ Esta obra se publicó por primera vez - junto con una recopilación de escritos publicados anteriormente por su autor (Del Yo como principio de la filosofía, Cartas sobre dogmatismo y criticismo, Sobre la relación de las artes plásticas con la naturaleza)- en 1809 en un volumen titulado Escritos filosóficos (F. W. J. Schelling's philosophische Schriften. T. I. Landshut, 1809). Valga, pues, el presente ensayo como una modesta conmemoración.

${ }^{9}$ F. W. J. Schelling, Investigaciones filosóficas sobre la esencia de la libertad humana y los objetos con ella relacionados. Ed. y trad. de Helena Cortés y Arturo Leyte. Barcelona, Ánthropos, 1989, pp. 103-105. 
ontológico general. Desde aquí se trata de plantear el problema de la libertad del ser humano en el plano de su existencia concebida como escindida de la naturaleza y, a la vez, enraizada en el conflicto que atraviesa y se manifiesta en la totalidad de lo presente.

El arribo de la filosofía a su punto central - la oposición entre necesidad y libertad-conlleva una mutación de la misma filosofía respecto al modo como ésta se definía en términos de espíritu y naturaleza. La filosofía, considerada como la máxima actividad del espíritu subjetivo frente a la naturaleza meramente objetiva, se asumía como un ejercicio libre opuesto al mecanicismo imperante fuera de ella. En cambio, al asumirse el pensamiento filosófico constituido por la actividad desatada por la oposición entre libertad y necesidad que atraviesa a la naturaleza y, distintamente, se prolonga en el espíritu, su identidad se modifica; la filosofía está constituida por la misma oposición originaria que sostiene y constituye a la totalidad. Pensar es asumir y expresar la verdadera oposición entre necesidad y libertad que funda y, a la vez, se manifiesta en la totalidad. La filosofía se posesiona de sí misma expresando ese conflicto, y esta expresión no es nunca completamente transparente porque el fundamento del conflicto permanece oculto.

Para apuntar al concepto correcto de libertad, Schelling inicia sus investigaciones destacando "el sentimiento del hecho real de la libertad en cada cual" como algo que, para ser desentrañado, exige "una pureza y hondura de espíritu mucho mayores de lo habitual", ya que el concepto de libertad debe relacionarse "con la totalidad de una concepción científica del mundo" ${ }^{10} \mathrm{El}$ sentimiento de la libertad de cada uno debe ser esclarecido concibiéndolo y relacionándolo con la totalidad sistemática que se forja conceptualmente en la filosofía. Ningún concepto, dice Schelling, se determina de manera aislada; sólo la relación con la totalidad lo prueba y consuma filosóficamente, por lo tanto, el concepto de libertad, si se muestra como real, más que un concepto subordinado, tiene que ser un concepto central y rector del sistema. Determinar el concepto de libertad sólo es posible relacionándolo con la totalidad que se estructura en el sistema.

Frente a los que consideran que la libertad y el sistema son incompatibles ${ }^{11}$ -la libertad trastoca o conmociona la unidad de la totalidad que se debe mos-

${ }^{10}$ Ibid., p. 111.

11 "Desde los orígenes del pensamiento moderno -y podríamos decir que la modernidad se muestra en esto clarísima heredera del pensamiento medieval-se ha identificado 
trar en un sistema, por lo tanto, en éste tiene que imperar ineludiblemente la necesidad, que es la única que se identifica con la razón-, Schelling afirma simultáneamente a "la razón apremiante de unidad" y el "sentimiento que reposa sobre la libertad y la personalidad" 12 y esta afirmación que mantiene la libertad personal y la razón abierta a concebir la unidad de la totalidad se debe a que precisamente ese sentimiento y ese apremio de la razón establecen el requerimiento de relacionar a la libertad con la totalidad desde una peculiar concepción de la filosofía que asume la oposición de libertad y necesidad.

La libertad, para determinarse como lo que propiamente es, requiere de su distinción frente a la necesidad; ésta es la que, oponiéndosele, permite que la libertad se afirme. En la oposición afirmativa de los contrarios la filosofía encuentra su impulso al conocimiento, el cual se alza como razón confrontándose con aquello que en sí mismo no está definido como un proceso puramente racional. La filosofía, tal como Schelling la concibe y la pone en obra, tiene su tarea irrenunciable en determinar a la libertad en conexión con la totalidad, y esto por considerar que, en dicha tarea, se fortalece el concepto mismo de libertad y se valora a la filosofía como concreción conceptual de la existencia y su fundamento. ${ }^{13}$ La tarea de asumir la contradicción sin renunciar a conectarlas en la unidad de la totalidad es un signo que manifiesta la vitalidad de la propia filosofía. Pero esta concepción de la filosofía -siendo para Schelling la más elevada- no es la única posible. Desde aquí se trata de revisar ciertos momentos históricos de la propia modernidad filosófica para remontar el modo abstracto en que en ella se ha fijado el problema de la libertad y la necesidad.

razón, sistema, concepto con la necesidad, y en muchos casos en dicha necesidad se ha hecho coincidir la necesidad física y lógica, mientras que del otro lado se situaban el azar, la indeterminación, lo ilógico y lo irracional como dominios propios de la libertad. Schelling ha conducido la especulación filosófica a la cumbre de sí para mostrarnos que la necesidad no excluye la libertad, lo cual es tanto como decir que la necesidad, y lo necesario, no constituyen el opuesto de la libertad, y que la razón misma, que es esencialmente sistemática, es por ello libertad sin dejar de ser necesidad" (Fernando Pérez-Borbujo Álvarez, Schelling: el sistema de la libertad. Barcelona, Herder, 2004, pp. 89-90).

${ }^{12}$ F. W. J. Schelling, op. cit., p. 111.

13 " [...] hasta el momento [...] la conexión del concepto de libertad con la totalidad de la concepción del mundo deberá seguir siendo objeto de una tarea necesaria, sin la solución de la cual incluso el concepto de libertad vacilaría y la filosofía perdería absolutamente todo su valor, porque esta gran tarea es el único e inconsciente resorte de toda aspiración de conocimiento, desde el grado más bajo al más elevado. Sin esta contradicción de libertad y necesidad, no sólo la filosofía, sino todo superior querer del espíritu se hundiría en la muerte propia de aquellas ciencias en las cuales tal contradicción no tiene aplicación. Evadir el problema renunciando a la razón se asemeja más a una huida que a una victoria" (ibid., p. 115). 
Se puede abandonar a la libertad asumiendo sólo a la razón e igualándola a la necesidad y, con esto, afirmar que "[...] el único sistema posible de la razón es el panteísmo, pero éste conduce inevitablemente al fatalismo". ${ }^{14}$ El panteísmo filosófico moderno, en su forma más elaborada, es el que se contiene en la Ethica, ordine geometrico demostrata de Spinoza, obra que ha sido objeto de una serie de malas interpretaciones originadas por una deficiente comprensión del principio de identidad. Schelling se las ve así con Spinoza cuya filosofía es considerada más atrayente que el cartesianismo por el paso decidido que "el trágico judío de Ámsterdam" (Unamuno) dio al hacer de "lo primero en sí" el punto de partida, concebido como aquello que se puede conocer con necesidad: lo primero en sí es la existencia necesaria, independiente de su ser para el sujeto. Esta confrontación le permite a Schelling desplegar la dimensión creadora del principio de identidad presente ya en su manera de concebir la relación entre fundamento y existencia.

La condena del panteísmo de Spinoza se resume en tres sentidos que se le atribuyen: todo es Dios, toda cosa individual es Dios, y las cosas no son nada en sí mismas. Estos sentidos que se le achacan a la filosofía de Spinoza son expuestas y desmontadas por Schelling con el fin de preparar su confrontación crítica con el también autor del Tratado teológico-político.

Todo es Dios. Dios se identifica totalmente con las cosas; el creador y lo creado se funden completamente. Esta interpretación es insostenible, puesto que, para Spinoza, sólo Dios es en sí mismo y se puede concebir a partir de sí mismo como existencia necesaria; las cosas finitas, en cambio, son en otro y sólo se pueden concebir desde este otro. El concepto de Dios como sustancia precede ontológicamente a las cosas por lo cual la mera reunión de éstas nunca puede ser equiparable a la esencia que las precede. Toda cosa individual es Dios. Decir que para Spinoza la cosa singular es Dios modificado es absurdo, ya que un Dios modificado no es Dios propiamente. Las cosas no son nada en sí mismas. Esta tercera propuesta del sentido del panteísmo también es errada, porque Spinoza no afirma la nulidad del ente individual; él mantiene que fuera de la sustancia no hay nada y, por lo mismo, las cosas singulares son la propia sustancia considerada en sus consecuencias. La sustancia infinita considerada como absoluta y la sustancia infinita vista en sus modificaciones o consecuencias no son equivalentes. ${ }^{15}$

${ }^{14}$ Ibid., p. 117.

${ }^{15}$ Cf. ibid., pp. 121-133. En su confrontación explícita con la filosofía moderna, Schelling precisa el matiz de su interpretación del panteísmo de Spinoza: "[...] el sentido de la proposición 'Dios es todo' no solamente se reduce a que él es todo según su esencia, ya que ésta es siempre simple (prius affectionibus) y una, sino que es todo según su existencia; considerado como existente en el despliegue de todo su ser y, por decirlo así, fuera de sí, Dios es la totalidad de todas las determinaciones del ser, pero no lo es 
Schelling aclara el origen de estas burdas interpretaciones del panteísmo de Spinoza y esta aclaración le permite retomar el problema de la libertad. La razón de las interpretaciones deficientes "reside en el mal entendimiento generalizado del principio de identidad o del sentido de la cópula en el juicio". ${ }^{16}$ Para Schelling, la identidad expresada en la cópula (A es B) no implica una indistinción absoluta entre los términos que componen la proposición, de tal modo que éstos sean equiparables. La identidad no implica que todo venga a ser igual, sino el desdoblamiento diferenciador de lo uno en lo otro. La dialéctica más que la igualdad es la que nos da la clave para comprender el principio de identidad.

Dicho principio no expresa una unidad que girando en el círculo de la igualdad no sería progresiva y por ello mismo sí insensible y sin vida. La unidad de este principio es inmediatamente creadora [...] y el principio del fundamento es por ello tan originario como el de la identidad. Por eso mismo, lo eterno debe ser también inmediatamente, y tal y como es en sí mismo, fundamento. Aquello de lo que él es fundamento por su esencia, es un ser dependiente en esa misma medida y también, conforme al punto de vista de la inmanencia, un ser comprendido en él; pero la dependencia no anula la subsistencia por sí, ni tampoco tan siquiera la libertad. ${ }^{17}$

¿Qué significa que la unidad del principio de identidad sea inmediatamente creadora? ¿Por qué el principio de identidad es originario en la misma medida que el principio del fundamento? La identidad del fundamento implica ya una diferencia: el fundamento mismo en tanto tal y lo fundamentado por la esencia del fundamento. Y si pensamos al fundamento no como trascendente sino como inmanente, como identidad inmediatamente creadora de lo otro de sí mismo, entonces lo fundamentado queda comprendido en el fundamento, de tal modo que en lo consecuente o dependiente no se anula la subsistencia por sí ni la libertad.

La libertad hay que pensarla no sólo en relación con lo ente de suyo sino también en referencia a lo que ha llegado a ser, a aquello que -a diferencia de

considerado en su esencia, en sí o en su estado de ocultación. Ésta es una distinción muy importante que se suele pasar por alto con mucha frecuencia" (F. W. J. Schelling, Lecciones muniquesas para la historia de la filosofía moderna, p. 147). "Dios es todo" significa que Él se despliega en la totalidad de lo existente; Él es la totalidad de las determinaciones del ser en tanto manifiesto fuera de sí. En cambio, Dios mismo pensado en tanto esencia en sí oculta no es comparable con nada de lo existente.

${ }^{16}$ Ibid., p. 123.

${ }^{17}$ Ibid., pp. 133-135. 
Dios- no tiene en sí mismo el dominio sobre la condición de su existencia. Con esto se abre el problema de pensar la esencia de lo dependiente en tanto tal rebasando la consideración que lo reduce a multiplicidad diferente como mera consecuencia de la unidad idéntica que la determina.

Un individuo orgánico - pone por caso Schelling- llega a existir a través de otro y, en este sentido, es dependiente del otro según el devenir, pero no según el ser. "Todo individuo orgánico, en calidad de ser que ha devenido, es sólo a través de otro, y por lo tanto, dependiente de él según el devenir, pero en absoluto según el ser". ${ }^{18}$ Devenir o llegar a ser a partir de otro significa que lo devenido depende de lo que lo fundamenta, pero no significa que el ser mismo de lo que deviene sea igual, esto es, se disipe en el ser que, fundamentándolo, lo originó. Devenir desde un fundamento significa más bien que lo fundamentado se diferencia en su ser de aquello que lo fundamenta y de lo cual depende según el devenir: ser dependiente es distinto que ser originario, aunque no sea posible ser el uno sin el otro. Evitando el error de "confundir la identidad con la igualdad" 19 podemos pensar uno y otro -fundamento y fundamentado, identidad y diferencia- afirmando que el antecedente y el consecuente, lo independiente y lo dependiente expresan la dialéctica de lo uno es lo otro ${ }^{20}$ como lo mismo diferenciado y, en tanto tales, subsistentes por sí mismos. El devenir de uno a otro como afirmación de lo mismo diferenciado conlleva que la existencia en general subsiste por sí misma, porque ella es la revelación del ser que, alterándose, se manifiesta a sí mismo. El ser, como fundamento y existencia, como identidad y diferencia, se produce a sí mismo de tal modo que uno es lo otro, pero lo que se manifiesta no agota o consuma lo que se oculta. El ser es devenir que une y escinde producción y producto; adviniendo o llegando a ser en sus producciones, el ser mismo se potencia desde lo material a lo orgánico, de lo orgánico a lo vivo y de éste a lo consciente.

La naturaleza es así pensada como una actividad viva de autoorganización necesaria, y esta concepción se convierte en la parte real de la filosofía que se continúa en la parte ideal al concebir el modo como la conciencia, afirmada latentemente -incubándose- desde la naturaleza, se desarrolla a sí misma

${ }^{18}$ Ibid., p. 135.

${ }^{19}$ Ibid., p. 127.

${ }^{20}$ En su comentario al texto de Schelling, Heidegger aclara la dialéctica presente en la enunciación "lo uno es lo otro" de la siguiente manera: "Un uno es sólo lo que él es, en su diferencia respecto del otro. Este ser diferente frente a lo otro y ser en ese respecto lo otro mismo, pertenecen a lo uno, y por ello es lo uno también y esencialmente lo otro, y a la inversa. El 'es' no significa precisamente un vacío 'ser uno y lo mismo', pues lo uno no es, justamente, uno y lo mismo que el otro, sino diverso; pero en la diversidad como referencia se copertenece con él: ambos son 'idénticos' en sentido superior, propio" (Martin Heidegger, Schelling y la libertad humana. Trad. de Alberto Rosales. Caracas, Monte Ávila, 1990, p. 96). 
en la concreción de la historia en la que se despliega la libertad. ${ }^{21} \mathrm{Y}$, desde aquí, la racionalidad reducida a mecanicismo por Spinoza, y su consiguiente fatalismo, ${ }^{22}$ es subvertida por el idealismo que, al dinamizar el principio de la naturaleza, alcanza una consideración superior de ella al reconocer la unidad diferenciada de lo dinámico con lo anímico y de éste con lo espiritual. Con esto, dice Schelling, el idealismo alcanzó "el auténtico sistema de razón" al afirmar, desde el principio dinámico y orgánico de la naturaleza, a la libertad como "el último acto potenciador" por el cual "toda naturaleza se transfigura en sensación, en inteligencia, y finalmente, en voluntad". ${ }^{23} \mathrm{Y}$ al acceder la voluntad a la autoconciencia se inicia el camino desde el cual, retrospectivamente, se despeja la clave del ser.

En suprema y última instancia no hay otro ser que querer. Querer es el ser originario y sólo con éste concuerdan todos los predicados del mismo: ausencia de fundamento, eternidad, independencia respecto al tiempo, autoafirmación. Toda la filosofía aspira sólo a encontrar esta suprema expresión. ${ }^{24}$

${ }^{21} C f$ F. W. J. Schelling, Sistema del idealismo trascendental. Trad., pról. y notas de Jacinto Rivera de Rosales y Virginia López Domínguez. Barcelona, Ánthropos, 1988, pp. 195 y ss.

${ }^{22}$ Para Schelling, Spinoza es fatalista, esto es, niega la libertad, pero no por su panté́smo, sino por su mecanicismo desde el cual todo, incluido Dios, es concebido como cosa sometida a determinaciones causales. "El fallo de su sistema no reside en modo alguno en que sitúe las cosas en Dios, sino en que sean cosas; reside en el concepto abstracto de los seres del mundo, esto es, en el de la propia sustancia infinita, que para él es también a su vez una cosa. Por ello, sus argumentos contra la libertad son muy deterministas y de ningún modo panteístas. También considera la voluntad como una cosa y después demuestra, como es natural, que en cada actuación debe estar determinada por otra cosa, la cual, a su vez, está determinada por otra y así hasta el infinito. De ahí viene la falta de su sistema, la aridez de la forma, la pobreza de los conceptos y fórmulas, la implacable rigidez de las determinaciones, que armoniza a la perfección con su modo abstracto de consideración, y de ahí también, consecuentemente, su visión mecanicista de la naturaleza" (F. W. J. Schelling, Investigaciones filosóficas sobre la esencia de la libertad humana y los objetos con ella relacionados, p. 143.) A pesar de esta crítica, Schelling reconoce el papel decisivo de Spinoza en la modernidad filosófica al llevar el principio subjetivo de Descartes (lo primero para el yo) a lo primero en sí. "El sistema spinozista será siempre, en cierto sentido, el modelo". Sin embargo, este modelo fatalista requiere ser transformado en un sistema de la libertad. "Un sistema de la libertad -como contrafigura perfecta del spinozismo, pero con la misma generalidad y simplicidad-sería propiamente lo más alto" (F. W. J. Schelling, Lecciones muniquesas para la historia de la filosofía moderna, p. 139.)

${ }^{23} \mathrm{~F}$. W. J. Schelling, Investigaciones filosóficas sobre la esencia de la libertad humana y los objetos con ella relacionados, pp. 145-147.

${ }^{24}$ Ibid., p. 147. 
El ser originario en tanto tal es querer. El querer originario carece de fundamento, pero, precisamente por ser voluntad, no se desvanece en la nada sino que, revelándose y afirmándose a sí mismo, se aparece en la totalidad de la presencia de la naturaleza. El ser originario, en tanto voluntad abstraída de su propia concreción, no es nada determinado, no existe siendo esto o aquello y, en este sentido -y sólo en este sentido- él es independiente del tiempo; abstractamente el mero querer es lo que "precede" su propia afirmación en el tiempo: el ser originario es la condición de posibilidad de toda presencia y toda presencia es la revelación alterada de la misma voluntad. El ser originario es voluntad eterna autoafirmándose existentemente en el tiempo.

Podemos pensar, esto es, crear una idea referida a un ser in-determinado como puro querer y esta idea admite la referencia al querer como ser originario independiente del tiempo; es una mera idea que remite abstractamente al querer-antes-del-inicio de su autoafirmación, pero -y esto se descubre en la contradicción que dicha idea entraña- al iniciar realmente esta afirmación -es decir, siempre, eternamente- el ser mismo, por así decirlo, se diferencia existentemente en el tiempo. La suprema expresión de la filosofía radicaría en poder dar cuenta de la unidad de identidad y diferencia, de mismidad y alteridad entre el ser libre eternamente ausente de fundamento que en su autoafirmación necesaria no aparece como tal, sino como lo otro de sí mismo; como existente temporal. La autoafirmación de la esencia eterna en su propia alteridad temporal es el elemento creador descubierto en los principios de identidad y de fundamento.

Éste es el punto a donde la filosofía, en su asunción idealista, sobre todo, por el propio Schelling en su filosofía de la naturaleza, ha llegado y sólo desde aquí es posible abordar la investigación sobre la libertad. El idealismo ha sido una revolución filosófica profunda porque no sólo modificó el modo en que la filosofía se asume sino porque, sobre todo, transformó radicalmente el modo como se piensa el ser en sí mismo, en la naturaleza y en la historia. ${ }^{25} \mathrm{Y}$, pretendiendo ir más allá de la revolución idealista para abrirse a "la superior filosofía de nuestro tiempo, y sobre todo al superior realismo de la misma", ${ }^{26}$ Schelling piensa a la existencia de la naturaleza originada desde un fundamento "vivo de fuerzas de movimiento" ${ }^{27}$ y, basándose en ello, propone una

${ }^{25}$ El carácter revolucionario del idealismo filosófico es afirmado tajantemente por Schelling: "La idea de convertir de pronto a la libertad en el Uno y todo de la filosofía ha liberado al espíritu humano en general y no sólo en relación consigo mismo, y ha provocado en todas partes de la ciencia un cambio más profundo y fuerte que el de cualquier revolución anterior (ibid., pp. 147-149).

${ }^{26}$ Ibid., p. 149.

${ }^{27}$ Ibid., p. 159. 
reunión de idealismo y realismo (real/idealismo) como un sistema vivo ${ }^{28}$ que, como filosofía superior de la modernidad, posibilite fundar un concepto de libertad ya no general y formal -libertad como aquello que acontece por sí mismo realizándose en su esencia o como mera autodeterminación subjetiva consciente- como la piensa el idealismo dogmático y crítico, sino un concepto positivo presentándolo en toda su dificultad como capacidad para el bien y para el mal.

"Pues el idealismo sólo ofrece concretamente, por un lado, el concepto más general de libertad, y por otro el meramente formal. Y sin embargo, el concepto real y vivo es el de que la libertad es una capacidad para el bien y para el mal". ${ }^{29}$ Con esta crítica al idealismo -que, a la vez, es una autocrítica de los que el propio autor de las Cartas sobre dogmatismo y criticismo pensó en las etapas anteriores de su travesía filosófica-Schelling se alza como aquel que abre el pensar más allá de la posición metafísica fundamental del idealismo. Desde aquí lo que nos interesa afrontar es lo siguiente: ¿cómo pensar la identidad del concepto positivo de libertad con el concepto de necesidad? y ¿de qué manera la decisión humana expresa el conflicto entre libertad y necesidad? ${ }^{30}$ Enfrentar estas preguntas requiere determinar el modo como la libertad opera en la existencia humana para analizar y criticar su esencia formal propuesta por el idealismo y, a su vez, este análisis y esta crítica son precedidos por la discusión de su concepto habitual.

\section{II}

El concepto habitual de libertad es el que considera que ésta es una facultad totalmente indeterminada, de modo que podemos presumir de ser libres cuando, ante la posibilidad de optar por dos opciones distintas, optamos por una o por otra sin ningún motivo determinante. Este concepto de libertad -dice Schelling- tiene el mérito de presentarnos la idea del ser humano caracterizado

28 "El idealismo es el alma de la filosofía; el realismo su cuerpo. Sólo la reunión de ambos constituye un todo vivo. El último nunca puede proporcionarnos el principio, pero tiene que ser el fundamento y el medio en los que el primero se hace efectivo, toma carne y sangre. Si a una filosofia le falta este fundamento vivo, lo cual es normalmente señal de que originariamente también el principio ideal era escasamente efectivo en ella, entonces se pierde en aquellos sistemas cuyos conceptos abstraídos de aseidad, modificaciones, etc., se hallan en el más tajante contraste con las fuerzas de la vida y la plenitud de la realidad efectiva (ibid., pp. 159-161).

${ }^{29}$ Ibid., p. 151.

${ }^{30} \mathrm{El}$ espinoso tema de la libertad como capacidad para el bien y para el mal lo hemos abordado en otro ensayo de próxima publicación por la Universidad Ramón Lull de Barcelona, España. 
por la indecisión originaria, sin embargo, la aplicación de este concepto a las acciones singulares nos conduce al absurdo porque no explica por qué un ser humano se decide por A o por -A. Considerar a la libertad como arbitrio indeterminado -suponer que puedo hacer esto, pero también, si lo deseo, puedo hacer lo contrario- no demuestra la ausencia de determinación, sino que muestra que por ignorar la causa determinante se concluye que ésta no existe cuando en realidad lo que opera aquí es precisamente el proceso de determinación a través de la ignorancia. ${ }^{31}$ La libertad como arbitrio absoluto introduce la contingencia en las acciones humanas singulares y, con esto, deshace todo vínculo entre la libertad y el destino. Y Schelling, que pretende unificar sistemáticamente a la totalidad desde el concepto central de la libertad, no puede aceptar a la libertad humana como productora de contingencia, ya que ésta, en tanto azar, rompe la unidad de todo y niega a la razón. "Pero el azar es imposible, contradice a la razón tanto como a la unidad necesaria del todo; y si no se puede salvar a la libertad más que mediante la total contingencia de las acciones, entonces es que no es salvable en absoluto". ${ }^{32}$ La libertad como indecisión originaria del ser humano en general, cuya puesta en obra permea de contingencia todas y cada una de las acciones singulares, es un concepto totalmente desechable para Schelling.

Y, de la misma manera, a pesar de considerarla preferible a la anterior, tampoco acepta la concepción que niega la libertad, sumiendo a todas las acciones en una necesidad empírica imposible de romper: todo lo que hacemos estaría irrevocablemente constreñido por representaciones u otras causas escondidas en nuestro pasado y a las cuales no podemos controlar en el momento en que realizamos algo.

Si queremos acceder al modo como el concepto real y positivo de libertad se manifiesta en nuestros actos tenemos que desmarcarnos tanto del concepto de libertad como decisión originaria que desemboca en el azar como del concepto de necesidad que sume toda acción en la cadena causal empírica. Estas dos concepciones no sólo se contradicen abstractamente entre ellas sino que ambas excluyen toda oposición entre libertad y necesidad, ya que para el arbitrio absoluto no hay nada necesario en las acciones, y, para el determinismo empírico, la libertad como poder de decisión es imposible. La libertad reducida a espontaneidad interna y la necesidad como mera determinación externa coinciden en la unilateralidad de lo que postulan y, al pretender universalizar su postura particular, obstaculizan a la filosofía en su propósito de pensar la oposición entre libertad y necesidad como la oposición superior y verdadera.

${ }^{31}$ Cf. ibid., p. 223.

${ }^{32}$ Ibid., pp. 223-225. 
A ambos [espontaneísmo y determinismo] les resulta igual de desconocida aquella superior necesidad que se encuentra igual de alejada del azar y de la obligación, esto es, de un proceso de determinación externo, y que no es en realidad más que una necesidad interna que brota por sí misma de la esencia del que actúa. ${ }^{33}$

El camino para la superación de la contradicción abstracta entre libertad y necesidad -aquella que para mantener uno de los elementos suprime al otro- se inicia reconociendo la presencia de la necesidad en el interior de lo que somos, y esta necesidad tiene su manantial en nuestra propia esencia. La necesidad suprema es interna, puesto que surge por sí misma de la esencia del que actúa. Si esta necesidad brota por sí misma es que no está determinada por nada externo; es libre, por lo tanto ¿necesidad y libertad coinciden indistintamente en la esencia del que actúa? Si esto es así, ¿cómo podemos seguir hablando de oposición entre libertad y necesidad? y ¿cómo, si son lo mismo, libertad y necesidad se afirman cada una oponiéndose a la otra? Afrontar estas preguntas requiere mantener lo que Schelling nos ha dicho sobre el principio de identidad como un principio creador: lo libre es necesario, lo necesario es libre. Libertad y necesidad no son iguales; son lo mismo en tanto cada una, para afirmarse, se opone a la otra diferenciándose de ella. Y esta afirmación de lo mismo diferenciado acontece también en el ser humano.

El inicio del camino que, recorriéndolo, permite arribar al planteamiento de la oposición entre libertad y necesidad, en donde la primera se afirma como capacidad para el bien y para el mal, ha sido desbrozado por el idealismo, cuyo concepto formal de libertad permite superar las nociones habituales de libertad y necesidad, así como su contradicción abstracta. El idealismo es aquí Kant al que Schelling no cita, sino que glosa de manera parcial destacando el papel ontológico de la libertad como esencia incondicionada del hombre.

El idealismo ha sido el primero en elevar la doctrina de la libertad a esa única región en la que puede ser comprendida. Según él, la esencia inteligible de cada cosa, y sobre todo del hombre, se encuentra fuera de toda conexión causal, así como fuera o más allá del tiempo. Por ello nunca puede ser determinada mediante algo que la preceda, en cuanto que, antes bien, es ella misma la que precede, no tanto temporal como conceptualmente, en tanto que unidad absoluta, a cualquier otra cosa que se encuentre o pueda aparecer en ella; tal unidad siempre tiene que encontrarse completa y acabada para que una acción o una determinación singular sean posibles en ella. ${ }^{34}$

33 Ibid., p. 225.

${ }^{34}$ Idem. 
La esencia inteligible del hombre en general es la libertad que, como condición de posibilidad ontológica, precede y determina lo que aparece desde ella. Esta esencia es in-determinada puesto que no hay nada previo a ella que la condicione: la libertad en su unidad general es la condición de los actos concretos. Lo que se manifiesta desde la esencia inteligible del hombre es la acción libre que a sí misma se determina. La libertad, en tanto condición de posibilidad, es in-determinada o in-finita y, en tanto acto concreto, finito, ella misma se determina. Y la crítica de Schelling al concepto de libertad del idealismo kantiano consiste en que, según el autor de Las edades del mundo, "no hay ningún tránsito de lo absolutamente indeterminado a lo determinado". ${ }^{35}$ Y esto significa un salto radical en el modo en que la filosofía piensa nuestro ser. El ser que somos y que nos identifica no es una in-determinación, esto es, una in-finitud. Nuestro ser es radicalmente finito y, en tanto tal, determinado. Esta determinación finita, nuestra propia esencia, es nuestra naturaleza que, en tanto cuerpo, implica un nudo de deseos y pasiones que expresan un querer fundamental que se confronta y afirma adviniendo al entendimiento.

Por ello, el ser inteligible sólo puede actuar según su propia naturaleza íntima, al igual que sólo puede actuar de modo totalmente libre y absoluto, o lo que es lo mismo, la acción sólo puede proceder de su fuero interno según el principio de identidad y con una absoluta necesidad, la cual es también la única libertad absoluta pues sólo es libre aquello que actúa según las leyes de su propia esencia y que no se encuentra determinado por ninguna otra cosa ni dentro ni fuera de él. ${ }^{36}$

Lo que se deriva de aquí es la crítica al concepto de libertad como autodeterminación puramente consciente. Actuar es poner en acto nuestro ser y los actos concretos que realizamos no son resultados de una opción por la que, de manera consciente, un ser originariamente indefinido se determine; los actos que realizamos son la manifestación necesaria de lo que somos. Y, a la vez, no hay nada -salvo nuestro propio ser- que incida condicionalmente en lo que hacemos, por eso nuestro acto es libre; nuestro ser íntimo -la identidad de nuestra esencia, que es, en cada caso, única- es lo que se diferencia en los actos que, por lo mismo, aparecen como necesarios. No hay aquí hiato entre esencia y actos; los segundos son la expresión diferenciada de la primera. La unidad de libertad y necesidad es, así, establecida desde el aspecto creador del principio de identidad. Lo que surge es manifestación de la esencia, y ésta es la reunión conflictiva de libertad y necesidad.

\footnotetext{
${ }^{35}$ Ibid., p. 227.

${ }^{36}$ Idem.
} 
Pero es precisamente esa propia necesidad interna la que es ella misma la libertad, y la esencia del hombre es esencialmente su propio acto: necesidad y libertad están compenetradas formando una única y misma esencia que sólo considerada desde distintos lados aparece como lo uno o como lo otro, y que es en sí libertad, pero formalmente, necesidad. ${ }^{37}$

¿Cómo pensar desde aquí la oposición entre libertad y necesidad? y ¿cómo acontece el conflicto entre la misma esencia que en sí es libertad y formalmente es necesidad? El verdadero conflicto entre libertad y necesidad no acontece entre entes separados, de los cuales uno sea libre y el otro necesario; la contradicción superior se sitúa en el interior -constituyéndolo- de un mismo ente. Este ente es en sí mismo libre de modo tal que su poder de actuar está en él mismo, y lo que él puede hacer es su esencia que, por lo tanto, aparece necesariamente en sus actos. Así, los actos concretos no son arbitrarios o azarosos, sino necesarios. El ser libre es, por así decirlo, el que no se traiciona a sí mismo manifestando en sus actos lo que realmente no es; el ser libre actúa con-formándose a sí mismo porque libertad y necesidad, reunidas en el conflicto que les permite afirmarse propiamente, constituyen su esencia íntima.

Desde la concepción de la esencia como reunión (singular) de libertad y necesidad, Schelling se confronta críticamente con el pensador que llevó a cabo la radicalización del concepto de libertad de Kant, es decir, con Fichte. Fichte, abstrayendo al yo de toda relación con lo que no es el yo mismo (esto es: el no-yo), lo piensa como acto en el cual el yo mismo se pone alcanzando la autoconciencia: el yo, como autoconciencia, no es nada más que esa autoposición y, como actividad que por sí misma se pone y para sí misma se concibe, es absolutamente libre. Schelling, como ya hemos perfilado, pretende desmontar la hipóstasis moderna del sujeto y, por lo tanto, crítica al yo como actividad abstraída que a sí misma se pone alcanzando la autoconciencia.

Pero esta conciencia, hasta donde es pensada meramente como autoaprehensión o conocimiento del yo, no es nunca primera y presupone ya, como cualquier otro conocimiento, al anterior ser. Ahora bien, este ser supuestamente anterior al conocer, no es ni un ser ni tampoco un conocer; es una autoposición real, un querer originario y fundamental que se hace él mismo algo y que constituye el fundamento y la base de toda esencialidad. ${ }^{38}$

La conciencia no es lo primero; ella no es principio ontológico: concebir al yo como poder absoluto de ponerse a sí mismo es atribuirle al ser derivado

${ }^{37}$ Ibid., p. 229.

${ }^{38}$ Idem. 
el poder originario del ser en tanto tal, esto es, del querer. Toda conciencia, por lo tanto, todo conocimiento presupone al auténtico ser. Lo que Schelling denomina como el auténtico ser (das eigenliche Sein) no es, en realidad, ni un ente definido ni, mucho menos, un conocer: el auténtico ser se hace y forma poniéndose realmente como algo; es el querer fundamental y originario ( $U r$ und-Grundwollen) y, en tanto tal, constituye el sustento de toda esencialidad. Nuestra propia esencia está precedida por este querer originario y, por ello, está determinada en sí.

No hay contingencia o arbitrariedad en nuestro ser y, en tanto es libre, significa que actuamos expresando ese mismo ser; lo que hacemos no es conducido por ninguna obligación sino expresión necesaria y voluntaria de lo que somos. ¿Qué es, entonces, lo que se constituye en el factor determinante en la decisión expresiva de nuestro ser? La tradición idealista considera que, al decidir qué hacer, la decisión se toma y se define exclusivamente en la conciencia. La libertad se reduce a la conciencia y los actos que la manifiestan son resultado de una decisión consciente. Frente a esto, Schelling coincide en que el hombre no es un ser decidido, sino que sólo él puede decidirse, sin embargo, el poder de decisión no lo sitúa fundamentalmente en la conciencia sino en un acto del ser originario -aquel querer por el cual todo se pone y hace realmente- que, en tanto tal, es un querer previo a la conciencia. El acto por el cual el hombre decide su ser convirtiéndolo en su constitución propia y necesaria acontece por el vínculo del ser humano con el ser originario. Y, desde este vínculo, nuestro ser es un querer que no es impuesto por ninguna obligación; es libre, y eso mismo que en nosotros quiere, es una fatalidad, por lo tanto, también es necesario. Y sólo confrontándonos con nuestra propia constitución necesaria podemos hacer de nuestra libertad destino.

El acto libre en y por el cual nos decidimos a ser lo que somos -el "acto libre que se convierte en necesidad" -39 no es un acto que se origina en la conciencia, sino un acto que la precede y la constituye y, por esta constitución, en la conciencia misma quedan excedentes del acto originario por el cual nuestro ser se determina y, por esta razón, todo hombre, con mayor o menor claridad, sabe que lo que hace es por su propia culpa. Todos hemos decidido, por nuestro vínculo con el ser-querer originario, ser lo que somos, y lo que hacemos es manifestación de nuestro ser propio, por lo tanto, todo lo que acontece como el trabado de lo que hacemos y sucede -toda la gama de interacciones humanas más o menos armónicas o conflictivas- es resultado necesario de nuestra expresión libre.

Así, frente a la idea de la predestinación de los hombres por decisión de Dios, Schelling afirma la predestinación por libertad.

${ }^{39}$ Ibid., p. 233. 
Nosotros también afirmamos una predestinación, pero en un sentido completamente distinto: decimos que el hombre actúa aquí del modo en que actuó desde la eternidad y desde el principio de la creación. Su actuar no deviene, como tampoco él deviene en tanto que ser moral, sino que es eterno por naturaleza. ${ }^{40}$

El hombre no posee "un ser anterior independientemente respecto a su voluntad" ${ }^{41}$ Somos nuestra voluntad en acto: actuamos libremente realizando lo que necesariamente somos. ${ }^{42} \mathrm{Y}$, por lo tanto, esta acción libre es la que nos ha llevado a la escisión del centro ubicándonos en éxodo hacia la periferia: el hombre es el ser ex-céntrico y con el acto por el cual se escinde de la unidad con todo afirmando su particularidad y singularidad existencial aparece necesariamente el mal.

De ahí la universal necesidad del pecado y de la muerte como verdadera extinción de la particularidad por la que toda voluntad humana tiene que pasar como a través de un fuego, a fin de ser purificada. A pesar de esta necesidad universal, el mal permanece siempre una elección propia del hombre; el mal, como tal, no puede ser hecho por el fundamento, y toda criatura cae por su propia culpa. ${ }^{43}$

Ser culpable es reconocer que nuestro ser está en falta por no tener en sí mismo las condiciones de su propia existencia. Y en este existir nos hemos traído con nosotros nuestra dote de deseos y apetitos que, alcanzando la conciencia, se afirman, en tanto tales, expresando el conflicto entre libertad y necesidad, y con esto abren la posibilidad del bien y del mal.

${ }^{40}$ Ibid., p. 235.

${ }^{41}$ Idem.

${ }^{42}$ Agudamente, Pérez-Borbujo detecta que tras esta extraña explicación de Schelling se encuentra Platón: "Schelling, en una visión trascendental, afirma que el ser del hombre radica en una decisión anterior al tiempo, cooriginaria con la posición del mundo. Dado que el ser es querer, el ser del hombre concreto consiste en una determinación original y necesaria de su libertad en el nivel preconsciente. Platón, en el mito de Er elaborado al final de la República, afirma en clave mítica que en un mundo preexistente hemos elegido un estilo determinado de vida, un cuerpo e incluso un lugar, y posteriormente, al cruzar las aguas del río Leteo antes de ingresar en el escenario del mundo, hemos olvidado esta decisión que, no obstante, está latente y nos constituye [...] Schelling, en la línea de Platón, sostiene que nuestro carácter y todas nuestras circunstancias son la encarnación de nuestra decisión. A esta idea responde el sentimiento de ser aquí como ya éramos desde la eternidad" (F. Pérez-Borbujo, Veredas del espíritu: de Hume a Freud. Barcelona, Herder, 2007, p. 142).

${ }^{43}$ F. W. J. Schelling, Investigaciones filosóficas sobre la esencia de la libertad humana y los objetos con ella relacionados, p. 221. 